\title{
Aprendizagem conceitual e apropriação da linguagem escrita: contribuições da teoria histórico-cultural ${ }^{1}$
}

\author{
MARIA TEREZINHA BELLANDA GALUCH*
}

MARTA SUELI DE FARIA SFORNI ${ }^{*}$

\section{RESUMO}

Este artigo tem como objetivo discutir a apropriação da linguagem escrita, especificamente no que se refere à ortografia, como uma aprendizagem conceitual. $\mathrm{O}$ trabalho se orienta pelo referencial de autores da Teoria Histórico-Cultural, sobretudo os estudos sistematizados por Leontiev (1983) no texto "Questốes psicológicas da teoria da consciência", no qual analisa processos psíquicos, como atenção e percepçáo, necessários à apropriaçáo de conceitos em atividades de ensino. Com a realização da pesquisa, foi possível explicitar a conscientização dos conceitos pelos estudantes como um dos aspectos que podem contribuir para a compreensão e o encaminhamento didático-metodológicos do ensino do conteúdo da linguagem escrita, nas quatro primeiras séries do ensino fundamental.

Palavras-chave: escrita, ortografia, aprendizagem, ensino fundamental.

${ }^{1}$ Este trabalho foi apresentado na 29a Reunião da Associação Nacional de Pós-Graduação e Pesquisa em Educação (Anped).

* Professora do Departamento de Teoria e Prática da Educação e do Programa de Pós-Graduação em Educação da Universidade Estadual de Maringá (UEM) (galuch@brturbo.com.br).

${ }^{* *}$ Professora do Departamento de Teoria e Prática da Educação e do Programa de Pós-Graduação em Educação da Universidade Estadual de Maringá (UEM) (martasforni@uol.com.br). 


\section{RESUMEN}

El objetivo de este trabajo es discutir la apropiación del lenguaje escrito, específicamente en lo que se refiere a la ortografía, como un aprendizaje conceptual. El trabajo toma como referencia a autores de la Teoría Histórico-Cultural, especialmente los estudios sistematizados por Leontiev (1983) en el texto "Cuestiones psicológicas de la teoría de la conciencia", en el que analiza procesos psíquicos, como atención y percepción, necesarios para la apropiación de conceptos en actividades de enseñanza. La investigación permitió explicitar la concientización de los conceptos por parte de los estudiantes como uno de los aspectos que pueden contribuir para la comprensión y el proceso didáctico-metodológico de la enseñanza de los contenidos del lenguaje escrito, en los cuatro primeros años de la enseñanza fundamental.

Palabras clave: escrita, ortografía, aprendizaje, enseñanza fundamental.

\section{ABSTRACT}

This article discusses the appropriation of written language, especially with regard to orthography, as concept learning. Analysis is based on authors of the Historical and Cultural Theory, especially Leontiev's systematic studies. In "Psychological Problems of the Conscience Theory" the author analyzes the psychic processes, namely attention and perception, which are necessary for the appropriation of concepts in teaching activities. Research demonstrated that students' awareness of the concepts is one of the aspects that can contribute to the didactic and methodological understanding and processing of the teaching of written language in the first four grades of the elementary school.

Keywords: written language, orthography, conceptual learning, elementary school. 


\section{A "CURVATURA DA VARA" NO ENSINO DA LINGUAGEM ESCRITA: SITUANDO A QUESTÃO}

Ed., 10 anos, acessa um site de busca na internet e, "secretamente", digita a palavra "secso". Ge., 12 anos, Ol., 13 anos, e Da., 15 anos, redigem uma lista de itens que precisam providenciar para um acampamento que estáo organizando. Dentre outras palavras, registram: "bichiga", "deterjente", "linguisa", "acanpamento". Nos dois casos, a linguagem escrita foi utilizada em situaçóes náo escolares, e cumpriu sua função social, estando carregada de sentido para as crianças que dela fizeram uso.

Diante dos erros ortográficos cometidos, poderíamos pensar que se trata de crianças com histórico de reprovação ou com "problemas de aprendizagem”. Todavia, é importante destacar que, ao contrário, são crianças cujo desempenho escolar é considerado satisfatório: todas já concluíram as quatro primeiras séries do ensino fundamental, e uma delas está cursando o ensino médio, com notas entre as maiores da sala. Este fato suscita algumas perguntas: Por que o conhecimento da linguagem escrita dessas crianças parece ser o de alunos em processo inicial de alfabetizaçáo? Por que, independentemente de terem frequentado a escola por quatro ou oito anos, continuam escrevendo da mesma forma, cometendo erros primários de grafia?

$\mathrm{O}$ caso tomado aqui como exemplo não é um fato isolado. $\mathrm{O}$ mau desempenho apresentado pelos alunos brasileiros em língua portuguesa, na avaliação realizada pelo Sistema de Avaliação da Educação Básica (Saeb), em 2003, bem demonstra que embora, atualmente, a escola tenha garantido que muitas crianças sejam alfabetizadas na educação infantil ou na primeira série do ensino fundamental, raramente lhes tem garantido a apropriaçáo do conhecimento da linguagem escrita.

Ao buscarmos elementos para a compreensão dessa questão, encontramos indícios que póem em dúvida a ideia corrente, segundo a qual a escola é resistente a mudanças. As práticas alfabetizadoras e o ensino da língua escrita, desenvolvidos nas últimas décadas em escolas brasileiras de educação básica, são reveladores de profundas alteraçôes. Podemos perceber que, por um lado, as atividades de "prontidão", as cartilhas e os exercícios de caligrafia foram praticamente banidos, e os exercícios de ortografia passaram a ocupar espaço secundário nas tarefas de sala de aula. Por outro, surgem novas práticas: incentivo à produção e uso de vários tipos de textos, dentre eles, os "portadores de textos do cotidiano" (jornais, receitas culinárias, bulas de remédio, dentre outros); as diferentes formas de o aluno grafar uma mesma palavra passaram a ser consideradas hipóteses e não mais erros; o tempo para a alfabetização extrapolou a primeira série do ensino fundamental e, com isso, 
o professor desta série deixou de ter a responsabilidade de que seus alunos comecem a segunda série dominando a leitura e a escrita.

Nessas mudanças, está implicada tanto uma nova forma de conceber o processo de aquisição da leitura e da escrita, cujos estudos de Emília Ferreiro e colaboradores exerceram grande influência, como a definição de novos objetivos para a educação, tendo em vista as transformaçóes no mundo do trabalho e a democratização do ensino. Podemos verificar no ensino da escrita o que Saviani (2000) denominou de "curvatura da vara". Da consideraçáo de que aprender a escrever não se restringe à compreensão do sistema da escrita, uma vez que envolve também o domínio de aspectos discursivos, derivou-se uma prática que privilegia a função social da escrita. A partir de então, passou-se a defender que os aspectos gramaticais e ortográficos somente poderiam ser trabalhados em textos produzidos pelos alunos. Como, geralmente, os alunos se encontram em níveis diferentes no processo de aquisiçáo dos conteúdos da língua escrita, cada texto apresenta aspectos específicos em relação ao código e à significação. Nesse sentido, torna-se praticamente impossível prever quando e como cada conteúdo será ensinado, ou seja, passa-se a não ter como organizar antecipadamente momentos ou etapas para o ensino dos aspectos notacionais; assim, muitas vezes, esses aspectos deixam de ser abordados. Portanto, assistimos à "curvatura da vara": da cartilha excessivamente estruturada, passa-se à ideia da impossibilidade de planejar com antecedência quaisquer sequências didáticas, ou até mesmo definir conteúdos mínimos da língua escrita a serem dominados em cada série, a menos que sejam conteúdos bastante amplos e, por isso, praticamente os mesmos durante as quatro primeiras séries do ensino fundamental.

Essas mudanças na forma de conceber o ensino da língua escrita têm seus desdobramentos: nos cursos de formação de professores, tornou-se sinônimo de conservadorismo falar em "como ensinar", julgando-se importante a compreensão de "como se aprende", bem como a reflexão sobre o processo de aprendizagem, acreditando-se que assim os futuros professores poderiam compreender o processo de construção do conhecimento vivido pela criança. No universo acadêmico e escolar se fortalecem ideias do tipo: "a criança supera problemas ortográficos com a prática de leitura"; "o importante é o conteúdo do texto produzido pelo aluno e não a sua forma"; "os aspectos ortográficos e gramaticais são superados ao longo da escolarização"; "o aluno deve produzir textos, e se ainda náo domina a escrita deve escrever do seu jeito"; "as dificuldades ortográficas são naturais e próprias da complexidade da língua escrita”. Essas ideias, comuns e predominantes entre muitos professores e equipes pedagógicas não destoam das orientaçôes contidas nos Parâmetros Curricu- 
lares Nacionais de Língua Portuguesa, como, por exemplo, a de que: "[...] é preciso que, tão logo o aluno chegue à escola, seja solicitado a produzir seus próprios textos, mesmo que não saiba grafá-los, a escrever como lhe for possível, mesmo que não o faça convencionalmente" (Brasil, 1997, p. 68).

\section{É POSSÍVEL O EQUILÍBRIO DA "VARA"?}

Após a década de 1990, diversos problemas, decorrentes das mudanças apontadas anteriormente, começaram a se tornar explícitos, e a questão passa a ser objeto de várias pesquisas. Alguns desses estudos trazem elementos que apontam a possibilidade de "equilíbrio da vara". Para Morais (2000), a compreensão de como funciona nossa escrita alfabética - tal como explicam Ferreiro e Teberosky (1985) na obra "Psicogênese da língua escrita" - não garante a aprendizagem da escrita correta das palavras. Ele defende que o sentido normativo da língua escrita deve ser levado em consideraçáo no ensino, pois nunca o sujeito estará liberado para construir o que quiser:

A luta por chamar-se ou não de "erros" as notaçóes infantis que desobedecem à norma parece-me refletir um sentido ideológico que, obviamente, estaria respaldado em boas intençôes: respeitar o percurso do aprendiz, não cercear a expressão escrita, etc.

Se sou favorável a toda pedagogia que persiga essas boas intençôes, lembro que não é substituindo a expressão "erros" por "variaçôes" ou "hipóteses" (ou qualquer alternativa similar) que alteramos substancialmente o quadro do ensinoaprendizagem da ortografia. (Morais, 2000, p. 16-17)

Essa questão também é objeto de análise de Rego e Buarque (2000). Para eles, o trabalho de Emília Ferreiro e Ana Teberosky trouxe várias contribuiçóes para a alfabetização, porém esse referencial de pesquisa "[...] ainda não caracterizou com clareza o progresso da criança após o seu ingresso na fase alfabética” (p. 21). Referindo-se a pesquisadores que têm procurado compreender e explicar o progresso em leitura e escrita após o ingresso na fase alfabética, afirmam: "Há um consenso entre estes pesquisadores de que o progresso da criança após o ingresso na fase alfabética não mais pode ser caracterizado por um modelo de estágios" (p. 22).

Observa-se, portanto, que, não só na concepção espontaneísta, segundo a qual a aprendizagem da linguagem escrita padráo ocorre por meio da leitura, como na concepção tradicional, cujo entendimento é o de que a criança se apropria dessa linguagem pelo treinamento do uso de palavras corretas, está implícita a ideia de que 
a criança aprende por meio da exposição repetida da grafia correta (Leal; Roazzi, 2000). Em ambas as concepçóes o objeto de conhecimento é tratado como se não envolvesse reflexão, análise e generalização - processos mentais imprescindíveis à apropriação conceitual (Sforni, 2004).

Nos próprios Parâmetros Curriculares Nacionais de Língua Portuguesa consta a afirmação de que "[...] para aprender a ler e a escrever, o aluno precisa construir um conhecimento de natureza conceitual" (Brasil, 1997 p.21). Todavia, apesar de na literatura acadêmica haver indicaçóes de que a aprendizagem da escrita não é de natureza perceptual e motora, e sim conceitual, poucos estudos sobre a aprendizagem conceitual têm sido tomados como base para se pensar a organização do ensino dessa área do conhecimento. Considerar a aprendizagem da escrita como um processo que envolve conhecimento conceitual significa dizer que, independentemente das especificidades da aprendizagem da linguagem escrita, há aspectos gerais acerca da aprendizagem conceitual que podem contribuir para a compreensão e o encaminhamento didático-metodológico do ensino desse conteúdo.

Nesse sentido, o presente artigo - que se insere no campo das discussóes sobre o desenvolvimento conceitual e o ensino de conteúdos escolares - tem por objetivo refletir sobre o ensino da linguagem escrita, tomando com referência estudos de autores da Teoria Histórico-Cultural, que podem contribuir para a apreensão e o encaminhamento didático-metodológico do ensino desse conteúdo, especialmente as teorizaçóes de Leontiev acerca da consciência, sistematizadas no texto intitulado "Questôes psicológicas da teoria da consciência".

\section{APROPRIAÇÃO DA LINGUAGEM ESCRITA: UMA APRENDIZAGEM CONCEITUAL}

Vygotsky (2000) explicita que a principal distinção na apropriação dos conceitos científicos e cotidianos é o vínculo existente entre os tipos de conceito e a tomada de consciência desses conceitos pelo sujeito. Os conceitos cotidianos são apreendidos em situações cuja consciência está voltada para o fenômeno, para o contexto, e náo exatamente para o conceito presente nele. Daí porque alguns tradutores da obra vygotskiana preferem usar o termo conceitos espontâneos quando se referem a conceitos dessa natureza. Os conceitos científicos, portadores de um grau mais elevado de abstração, não são tão evidentes nos fenômenos e contextos; para que sejam adquiridos, é preciso que a consciência do sujeito lhes seja intencionalmente dirigida. Caso contrário, corre-se o risco de não haver apropriaçáo do conceito e de se manter na superficialidade dos fenômenos. 
Vygotsky alerta para o fato de que os dois tipos de conceitos têm características diferentes e que não há como se apropriar de conceitos científicos seguindo os mesmos procedimentos com que se aprende os conceitos cotidianos. Isso significa que a tentativa de se promover uma "aprendizagem natural", inserindo o estudante em situaçóes de uso do conhecimento, pode não ser tão favorável à aprendizagem conceitual como, muitas vezes, pensamos. É preciso que o conceito esteja explícito, para que possa ser conscientizado pelos alunos na condiçáo de um instrumento de generalização.

Podemos, então, considerar que a instrução formal conduz à aprendizagem conceitual?

No texto "Questóes psicológicas da teoria da consciência", Leontiev nos tira a ilusão sobre a possibilidade de uma resposta simples à questão acima. Ele apresenta uma rica reflexão acerca da relação entre ensino e aprendizagem da qual é possível inferir algumas orientações para a organização do ensino de conceitos e, portanto, também para o ensino da linguagem escrita como um conhecimento de natureza conceitual.

Leontiev parte do seguinte questionamento: o que a criança conscientiza da instrução recebida? Como conscientiza? A resposta à primeira questão parece simples: ela toma consciência do material para o qual foi atraída a sua atenção. Mas, dessa resposta decorre, necessariamente, outra pergunta: qual é a relaçáo entre a organização do ensino proposto pelo professor e a atenção do aluno sobre o objeto do conhecimento?

Leontiev traz um exemplo que explicita essa relação. O professor apresenta aos estudantes pequenos textos com charadas e adivinhaçóes; propóe-lhes que adivinhem, desenhem e escrevam a palavra ou texto referente ao conteúdo da charada. A intenção do professor é a de que, de maneira lúdica, os estudantes tomem consciência do sentido do texto, do significado e da grafia correta das palavras e façam uso da escrita. Quer dizer, o objetivo, evidentemente, não é ensinar charadas ou desenho, mas ensinar a linguagem escrita, de modo especial, a escrita ortográfica. Todavia, apesar do caráter agradável da atividade, ela não assegura a conscientizaçáo do aspecto ortográfico, pois a atenção dos alunos está voltada para o conteúdo da charada e não, necessariamente, para a grafia das palavras.

Leontiev afirma que a conscientização do texto lido sempre se produz, mas o estudante, muitas vezes, se conscientiza de algo muito diferente do que deveria para o domínio consciente da escrita. Para ele, esse fenômeno - a coincidência entre o conteúdo proposto e o realmente conscientizado na atividade escolar - nos coloca 
diante de uma grande tarefa sob a perspectiva psicológica e por que não dizer, também, didática: a tarefa de compreender qual é o objeto da consciência do homem, o que conscientiza e sob quais condiçóes. "[...] a resposta habitual que se dá a essa questão consiste em inferir que o objeto da consciência é aquele para o qual se dirige a atenção do sujeito" (Leontiev, 1983, p. 198).

Mas o que leva algo a se tornar ou náo objeto de atenção do sujeito? O experimento realizado por Zinchenko, exposto por Leontiev, traz elementos elucidativos, por isso vamos apresentá-lo. Zinchenko entregou aos sujeitos uma folha na qual estavam desenhados quinze objetos, bem como quinze cartóes com desenhos diferentes dos da folha. Um grupo de alunos deveria dispor os cartóes sobre a folha, considerando a correspondência entre a primeira letra dos objetos desenhados; outro grupo deveria dispor os cartóes conforme a relaçáo mútua entre os objetos, por exemplo: machado e serra; caderno e caneta.

Nos dois casos, os objetos desenhados nos cartóes deveriam entrar no "campo de atenção" dos sujeitos. Apesar de a tarefa ter atraído a atenção dos dois grupos, o objeto da atenção lhes foi diferente. Quando os cartóes foram retirados de sobre a mesa, foi pedido aos sujeitos que recordassem o que estava desenhado em cada um deles. Os participantes do primeiro grupo (relação com as letras iniciais) lembraram-se de uma quantidade muito menor que os do segundo grupo. A explicação para esse fato é que, no primeiro grupo, era preciso distinguir e discriminar o objeto desenhado - tê-lo no campo da atenção - mas a consciência, propriamente dita, estava na estrutura fônica da palavra: no nome da figura. No segundo caso, o que estava na consciência do sujeito era o próprio objeto representado e a sua relação com o outro objeto, por isso, pôde, voluntária e facilmente, reproduzir-se na consciência. A experiência permite concluir que o que não é consciente, em geral, "[...] não pode reproduzir-se de maneira voluntária" (Leontiev, 1983, p. 200).

O autor faz novos questionamentos: "[...] o que encobre esta diferença na forma de conscientizar os objetos?" (p. 200). Segundo ele, a diferença está no dinamismo dos sujeitos na realização das duas tarefas, pois o objeto real da consciência depende da atividade que o sujeito realiza com o objeto. É assim que ele estabelece a relação entre "atividade e consciência". Isso não quer dizer que no experimento realizado por Zinchenko o primeiro grupo náo tinha percebido o significado de cada objeto. Certamente tinha, mas o conteúdo do que é percebido e do que é conscientizado, segundo Leontiev, não concordam diretamente.

Leontiev torna essa questáo mais clara, exemplificando: podemos dizer que uma pessoa se conscientiza das irregularidades da rua sobre a qual caminha, dos sujeitos 
que passam ao seu lado, das mercadorias expostas nas vitrines, ao mesmo tempo em que se mantém envolvido em uma conversa com outra pessoa? Não, afirma ele, pois o objeto da sua consciência é somente o conteúdo da conversa. Mas acaso não percebe o que o rodeia? Seus movimentos, toda a sua conduta na rua se encontra em completa correspondência com o que acontece ao seu redor, e, por isso, percebe o meio que o circunda. Na realidade, completa Leontiev (1983): "[...] o âmbito do conscientizado é relativamente estreito" (p. 201).

Dessa forma, podemos colocar em dúvida a eficiência de atividades de ensino em que a ortografia esteja presente de forma indireta. Podemos considerar que esses conhecimentos até sejam percebidos, mas o objeto da consciência do sujeito pode ser o conteúdo do texto que lê ou escreve e náo exatamente as regularidades e irregularidades da linguagem escrita. Assim, mesmo que na escola os alunos tenham interagido com os conhecimentos ortográficos, quando lhes são solicitados tais conhecimentos, é comum que sintam dificuldade em utilizá-los de forma consciente, porque o que não é consciente não pode ser reproduzido de maneira voluntária. Isso é o que nos revelam os erros ortográficos tomados como exemplo no início deste texto.

Leontiev (1983) se ocupa, ainda, de explicar, por que alguns fenômenos são conscientizados e outros apenas percebidos. Ele tece críticas à psicologia tradicional por esta ter se limitado a assinalar o papel dos fatores externos e internos no processo de conscientizaçáo, pois para essa perspectiva psicológica:

Os fatores externos são propriedades dos objetos, tais como, por exemplo, a intensidade de sua influência sobre os órgãos dos sentidos, sua novidade ou singularidade, o lugar que ocupam no espaço, etc. [...] Os fatores internos são, por exemplo, o interesse para um objeto determinado, o aspecto emocional, a presença da força de vontade, de percepçáo ativa, etc. (p.201)

Ao investigar o desenvolvimento das formas do reflexo psíquico e de sua dependência interna com a estrutura da atividade do sujeito, Leontiev (1983) aponta os limites da psicologia tradicional e estabelece dois critérios para a análise. Primeiro: “[...] a realidade que atua sobre o sujeito pode ser refletida em suas propriedades, relaçóes e nexos, e esse reflexo pode mediar as atividades do sujeito; não obstante, o sujeito pode não se conscientizar dessa realidade" (p. 202). A imagem subjetiva da realidade excita e dirige a atividade do sujeito, mas não lhe é "apresentada". Segundo critério:

[...] o conteúdo do que se manifesta ("o que se apresenta"[...]) ante o sujeito, ou seja, o que se conscientiza em um momento dado, é um conteúdo que ocupa, 
dentro da atividade que realiza, um lugar estrutural completamente determinado e que constitui o objeto de sua ação (o objeto direto desta ação) externa ou interna. (p. 202)

Neste sentido, o que entra ou náo no "campo da consciência" não depende de qual seja este conteúdo: estimulante aos sentidos, se novo ou habitual. Não depende sequer dos interesses, inclinaçóes ou emoçóes existentes a priori no sujeito perceptivo, mas se este conteúdo se lhe manifesta como objeto para o qual está diretamente dirigida sua ação. Nas palavras de Leontiev (1983):

Para que um conteúdo possa conscientizar-se é necessário que este ocupe dentro da atividade do sujeito um lugar estrutural de objetivo direto da açấo e, desse modo, entre em uma relação correspondente com o motivo desta atividade. Este postulado tem validade tanto para a atividade interna como para a externa, tanto para a prática como para a teórica. (p. 203)

Leontiev (1983) explica melhor essa ideia mediante um exemplo de um aluno que escreve algo. Do que ele se conscientiza quando escreve? Segundo o autor, depende do que impulsiona o aluno a escrever. Digamos que queira transmitir, expressar pela escrita suas ideias. Entáo, o objeto de sua consciência seráo as suas ideias, a forma de expressá-las por meio de palavras. É claro que ele deve, assim mesmo, perceber a representação gráfica das palavras que irá escrever - sem que isso seja o objeto real de sua consciência no momento dado -, as letras, palavras e oraçóes se apresentam subjetivamente ante ele como se estivessem "[...] escritas mais ou menos bem, mais ou menos mal" (p. 204). Mas se o objetivo for escrever com boa caligrafia? Então o objeto de sua consciência será a representação gráfica das letras.

Leontiev traz à tona outros aspectos vinculados à conscientização: as operaçóes conscientes, o uso de materiais visuais ou concretos, o sentido e o motivo da atividade. Não nos aprofundaremos nesses temas neste artigo por considerarmos que é necessário retomarmos aqui o objeto da nossa discussáo: a aprendizagem conceitual da linguagem escrita.

Vygotsky (2001), além de afirmar que não se aprendem conceitos científicos da mesma forma que conceitos cotidianos, apesar de haver um estreito vínculo entre eles, esclarece que o desenvolvimento da linguagem escrita não repete a mesma história do desenvolvimento da língua falada.

Os signos da linguagem escrita e o seu emprego são assimilados pela criança de modo consciente e arbitrário, ao contrário do emprego e da assimilação incons-

120 • Est. Aval. Educ., São Paulo, v. 20, n. 42, p. 111-124, jan./abr. 2009 
ciente de todo o aspecto sonoro da fala. A escrita leva a criança a agir de modo mais intelectual. Leva-a a ter mais consciência do próprio processo da fala. Os motivos da escrita são mais abstratos, mais intelectualísticos e mais distantes do emprego. (p. 318)

A riqueza da aprendizagem da linguagem escrita está no caráter consciente e, portanto, arbitrário. Vygotsky (2001) explica que a não-consciência e a não-arbitrariedade estão estreitamente vinculadas, e como isso ocorre no campo da linguagem:

[...] a criança domina certas habilidades no campo da linguagem mas não sabe que as domina. Essas operações são inconscientes. Isto se manifesta no fato de que ela domina tais operações espontaneamente, em determinadas situaçóes, automaticamente, isto é, domina-as quando a situaçáo, em suas grandes estruturas, a mobiliza para revelar essas habilidades; entretanto, fora de uma determinada estrutura, a criança não consegue fazer de forma arbitrária, consciente e intencional o que faz de modo não arbitrário. Logo, ela está limitada, é limitada para aplicar suas habilidades. (p. 320)

Essa situação é modificada pela aprendizagem do conhecimento sistematizado:

[...] na escola a criança aprende, particularmente graças à escrita e à gramática, a tomar consciência do que faz e a operar voluntariamente com as suas próprias habilidades. Suas próprias habilidades se transferem do plano inconsciente e automático para o plano arbitrário, intencional e consciente. (p. 320-321)

$\mathrm{O}$ acesso aos sistemas ortográficos e gramaticais permite à criança tomar consciência de sua própria atividade como usuária da língua e, assim, alcançar um nível superior no desenvolvimento da linguagem de modo geral. A apropriaçáo desses sistemas, todavia, não é espontânea, ela exige a mediação intencionalmente organizada tal como podemos depreender das reflexóes de Leontiev (1983), possibilitando o desenvolvimento de funçóes psíquicas superiores como a atenção arbitrária, a memória lógica e o pensamento abstrato. Nisso evidenciam-se as inter-relaçóes apontadas por Vygotsky entre ensino, aprendizagem e desenvolvimento.

\section{CONSCIENTIZAÇÃO DOS CONCEITOS PELOS ESTUDANTES: CONDIÇÃO PARA A APRENDIZAGEM}

As investigaçóes de Leontiev e Vygotsky, apontando a relação entre o objeto de conhecimento e a atividade do sujeito como determinante na conscientizaçáo desse 
objeto, nos alertam para os limites de novas práticas realizadas ou incentivadas nas escolas, cuja intenção é a de superar um modelo tradicional de ensino, buscando um novo modelo, mais democrático e agradável.

Analisemos o caso de a gramática ser abordada “[...] só como forma de sistematizar constataçóes feitas pela própria turma a partir de histórias completas e curtas, como fábulas, contos e piadas" (Pontuar..., 2002, p. 26). Se a intenção é a de que os estudantes dominem a escrita padrão, ao lerem histórias, fábulas, contos e piadas, pode não haver coincidência entre o conteúdo proposto e o realmente conscientizado pelos alunos. Qual pode ser o objeto da consciência dos estudantes nessas atividades? Possivelmente, o conteúdo dos textos e não a gramática. Mas isso não pode ocorrer concomitantemente? O desempenho escolar da maioria dos estudantes nos faz levar em consideração a afirmação de Leontiev, segundo a qual o âmbito do conscientizado é relativamente estreito.

Por outro lado, se a escrita correta náo for condição para a realização da atividade proposta, a atenção de quem a realiza tende a se deslocar para outros aspectos. Por exemplo: no caso do uso de receitas culinárias para se ensinar ortografia (Meu aluno..., 2003, p. 14), se a questáo é aproximar a escrita das suas situaçóes de uso, a forma como está grafada a palavra não é o objeto direto da atenção do leitor. Assim, a palavra açúcar pode estar grafada "azucar" "asucar", "açucar", "assucar", que cumprirá sua função no texto.

Podemos afirmar, ainda, que a atenção das crianças citadas no início deste artigo estava voltada para o conteúdo do site e da lista de objetos necessários para a realização do acampamento, e, por isso, as palavras "secso", "deterjente", "linguisa", "acanpamento" e "bichiga", carregadas de sentido para elas, são escritas e lidas sem causar qualquer estranhamento. Nesse caso, não há diferença se as palavras estão escritas "mais ou menos bem ou mais ou menos mal" (Leontiev, 1983, p. 204), pois a consciência está voltada para o objeto e não para a grafia. Pode ser que o ensino da linguagem escrita se dilua em atividades "com sentido", sem que seja objeto da consciência do estudante. Para que seja objeto de reflexão, análise e generalização, como toda e qualquer apropriação conceitual, é necessário que o ensino da linguagem escrita seja organizado de forma que o sujeito tome consciência do conteúdo a ser internalizado.

\section{TRILHANDO CAMINHOS}

É importante destacar que o propósito das discussóes levadas a termo neste artigo não é o de defender o retorno dos métodos tradicionais de ensino. Se o con- 
teúdo a ser ensinado é o ortográfico ele deve ser explicitado na atividade proposta e não diluído nela. Mas em que tipo de atividade? Em atividades em que a escrita ortográfica faça sentido para o aluno, ou seja, em situaçóes de letramento. As regras ortográficas devem ser "apresentadas" ao aluno à medida que se tornam necessárias à realização de ações, saindo, assim, da singularidade das situaçôes de letramento com vistas ao significado socialmente estabelecido, à sua universalidade. "Conhecer o significado é 'conhecer o singular como universal"” (Davydov, 1988, p. 249).

Nesse processo, a mediação do professor é imprescindível, pois o sujeito não se apropria do significado apenas por estar inserido em ambientes propícios, sejam eles alfabetizadores, letrados ou científicos. A interação com o objeto de conhecimento é importante, mas não suficiente. Como afirma Davydov (1988) “[...] o homem realiza a correlação entre o singular e o universal graças a uma série de ações mentais" (p. 249).

Sem que ocorram açóes mentais - conscientes e arbitrárias - é provável que o aluno desenvolva apenas um "sentido do idioma", com as limitaçóes que isso acarreta à sua autonomia como leitor e escritor. Nesse sentido, o trabalho com a ortografia náo representa um reducionismo das possibilidades formativas constantes nos textos. Ao contrário, mediante a apropriação desse conteúdo, o conhecimento notacional como objeto de conhecimento, quando internalizado, passa a ser instrumento para a produção escrita, tanto no contexto escolar como no contexto não-escolar.

\section{REFERÊNCIAS BIBLIOGRÁFICAS}

BRASIL. Ministério da Educação. Parâmetros curriculares nacionais: língua portuguesa. Brasília: SEF, 1997.

DAVYDOV, V. V. La Enseñanza escolar y el desarrollo psíquico. Habana: Editorial Progresso, 1988.

FERREIRO, Emilia; TEBEROSKY, Ana. Psicogênese da língua escrita. Porto Alegre: Artes Médicas, 1985. 284p.

LEAL, Tela Ferraz; ROAZZI, Antonio. A Criança pensa... e aprende ortografia. In: MORAIS, Artur Gomes de (Org.). O Aprendizado da ortografia. Belo Horizonte: Autêntica, 2000. p.99-120.

LEONTIEV, Alexei. Cuestiones psicológicas de la teoría de la consciencia. In:

Actividad, conciencia, personalidad. Habana: Pueblo y Educación, 1983. p. 192-245.

MEU aluno copia, mas não sabe ler. Nova Escola, v. 17, n. 161, p. 14, abr. 2003.

MORAIS, Artur Gomes de. Ortografia: este peculiar objeto de conhecimento. In: . O Aprendizado da ortografia. Belo Horizonte: Autêntica, 2000.

REGO, Lucia Lins Browne; BUARQUE, Lair Levi. Algumas fontes de dificuldade na aprendizagem de regras ortográficas. In: MORAIS, Artur Gomes de (Org.). O Aprendizado da ortografia. Belo Horizonte: Autêntica, 2000. p. 21-41.

PONTUAR? Depende do gênero, do leitor. Nova Escola, v. 17, n. 152, p. 26, maio 2002. 
SAVIANI, Dermeval. Escola e democracia: teorias da educação, curvatura da vara, onze teses sobre educação e política. 33.ed. Campinas: Autores Associados, 2000.

SFORNI, Marta Sueli de Faria. Aprendizagem conceitual e organização do ensino: contribuições da teoria da atividade. Araraquara: JM, 2004.

VYGOTSKY, L. S. A Construção do pensamento e da linguagem. São Paulo: Martins Fontes, 2000.

Recebido em: fevereiro 2009

Aprovado para publicação em: fevereiro 2009

124 • Est. Aval. Educ., São Paulo, v. 20, n. 42, p. 111-124, jan./abr. 2009 